\title{
A PERMANÊNCIA DOS ALUNOS DA FATEC TATUAPÉ EM 2015
}

\author{
http://dx.doi.org/10.5902/2318133822902
}

\author{
Rodrigo Vieira Campos \\ Ivanete Belucci Pires de Almeida \\ Centro Estadual de Educação Tecnológica Paula Souza, Brasil.
}

\begin{abstract}
Resumo
Neste texto apresentam-se resultados de um trabalho que buscou estudar os alunos que deixaram de frequentar a Fatec Tatuapé no ano de 2015, antes de concluir o curso em que estavam matriculados. Tal estudo é um esforço em busca de possíveis soluções para a questão da permanência do aluno em ambiente de ensino superior tecnológico, haja vista que outros estudos apresentam índices de aumento em relação a essa permanência dos alunos em instituições de ensino públicas e privadas. A coleta dos dados foi feita por meio de um questionário elaborado e desenvolvido pelo Centro Paula Souza, adaptado pela Fatec Tatuapé, como instrumento de medição para se perceber nesta instituição de ensino superior tecnológico, como o curso de Controle de Obras, oferecidos no período noturno, se comportava em relação à permanência dos alunos ingressantes no sistema de ensino. Foi possível perceber que este curso é o que apresenta maior índice de desistência, seguido do curso de Gestão Empresarial, oferecido na modalidade à distância. Considerou-se que os alunos do período noturno têm dificuldade em conciliar a jornada de trabalho com um curso de ensino superior. Destaca-se, ainda, que o ingressante na modalidade à distância tem relativa dificuldade em participar, estudar e se organizar para atender e executar as atividades propostas nesse ambiente de aprendizagem, além de sentir falta do contato interpessoal e extraclasse das aulas regulares.

Palavras-chave: permanência, ensino superior, educação tecnológica.
\end{abstract}

\section{THE STUDENTS’ SOJOURN OF FATEC TATUAPÉ IN 2015}

\begin{abstract}
This paper shows the results of a research that aimed the students who have stopped attending Fatec Tatuapé in 2015, before completing the course. This study is an effort to search for possible solutions for the issue of students' sojourn in higher technological education. Data collection was done through a questionnaire designed and developed by Centro Paula Souza, adapted by Fatec Tatuapé, as measuring instrument to realize this higher technological education institution, as the course Construction Managment, offered at night, behaved in relation to the permanence of students entering the education system. It was possible to see that this course is the one with the highest dropout rate, followed by the Business Management course, offered online. It was considered that the students that go to the college at night have difficulty reconciling the working day with a higher education course in this case. Also, the freshmen in online mode has relative difficulty in participating, study and arrange to meet and carry out the proposed activities in this learning environment, in addition to miss the interpersonal contact and extracurricular regular classes.
\end{abstract}

Key-words: sojourn, higher education, technological education. 


\section{Introdução}

$\mathrm{O}$ tema permanência escolar ganhou maior relevância nos últimos anos pois a cada semestre, nas esferas públicas e privadas, a taxa de alunos que deixam de frequentar um curso em uma unidade de ensino superior ou de escola técnica tem aumentado e, desse modo, despertado em educadores e gestores institucionais a reflexão sobre as causas desse movimento e também das possíveis interferências sociais e econômicas.

$\mathrm{Na}$ esfera privada a lógica é que para diminuir os custos matriculam-se mais alunos por sala de aula. Se esses alunos deixam de frequentar as aulas, estas passam a ser mais caras para a instituição, já que os custos se mantém, mas a arrecadação não. $\mathrm{A}$ consequência inevitável é a junção de turmas e o aumento de disciplinas na modalidade à distância, desvalorizando o trabalho do professor e vinculando suas atribuições a outros atores que compõe esse sistema racional de medir desempenho desalinhado com os processos de ensino e aprendizagem.

Em um momento de economia em baixa, aumento do desemprego e instabilidade política, muitos alunos não conseguem arcar com os custos de uma faculdade particular e abrem mão de estudar ou tentam ingressar em uma instituição pública, porém, devido à distância, concorrência e outros obstáculos, o aluno não vê outra saída senão o abandono dos estudos, mesmo sabendo que este é fundamental para a sua ascensão profissional e social.

$\mathrm{Na}$ esfera pública o problema é similar. Apesar de não buscar o lucro sucessivos cortes no orçamento exigem dos gestores um grande esforço para manter a oferta dos cursos e dos períodos letivos. A lógica aqui se repete: quanto menos estudantes em salas de aula maior é custo por aluno. Com o orçamento apertado reduzem-se as vagas em semestres seguintes, afetando os professores que lecionam nos cursos e a comunidade como um todo, pois se deixa de prestar um importante serviço à sociedade.

Para entender o que leva o aluno a abdicar de sua vaga na instituição de ensino pública torna-se importante investigar as causas dessa desistência, analisando o perfil do estudante e suas expectativas em relação à instituição e ao curso frequentado. Sabendose que cada unidade de ensino tem seu próprio contexto social e seus alunos têm os mais variados perfis, torna-se necessária a análise individual das unidades de ensino, pois cada uma possui diferentes cursos, estão instaladas em diferentes regiões, recebem alunos, na maioria das vezes de instituições públicas e que tem perspectivas de vida e de trabalho bastante heterogêneas, além de almejar melhores ocupações nos postos de trabalho.

As Fatecs, faculdades de tecnológicas do Estado de São Paulo, foram criadas no final dos anos de 1960, sendo pionerias as Fatecs de Sorocaba e São Paulo (Romanelli, 1978, Motoyama, 1995). A unidade Fatec Tatuapé organiza e compartilha com seus docentes, alunos e funcionários o plano de gestão 2014-2017. As metas foram traçadas pensando na conciliação de vários atores, como: coordenadores, professores, alunos e funcionários.

Devemos nos concentrar em atendimento prioritário à permanência dos alunos nos cursos, de forma agradável e responsável. O foco nas disciplinas foi alterado para os projetos e as salas de aula devem se transformar em ambientes presenciais focados no aprendizado do aluno. 
No período analisado tem-se como desafio implantar projetos nos seus três eixos tecnológicos de atuação, iniciação científica e capacitação pedagógica para o seu grupo de docentes e funcionários, no intuito de padronizar procedimentos e aumentar as conexões e os saberes entre os protagonistas desse processo, sempre com o olhar focado no aluno que iremos inserir no mundo do trabalho.

Ressalta-se que a educação tecnológica está organizada em função de eixos tecnológicos, criando com isso, diversas oportunidades de percurso formativo para o aluno, de maneira que suas aptidões, desejos e vocações sejam atendidos pelos diferentes cursos e programas de educação profissional e tecnológica (Brandão, 2012).

Há também a intenção de introduzir nesta esta unidade de ensino superior o curso de Tecnologia em Design de Produtos. Busca-se, com essas ações, estar em permanente estado de transformação, condição inovadora e com meta audaciosa de atendimento público de qualidade, para uma região altamente populosa e que merece novos cursos com novas perspectivas de trabalho.

Há uma preocupação dos gestores com os laboratórios da unidade e suas atividades, que devem ser oferecidas em cursos tecnológicos. Para equipá-los de forma a atender as necessidades de alunos e docentes, foram feitos contatos com algumas empresas e parcerias foram firmadas.

O presente trabalho investigou o perfil dos alunos que deixaram de frequentar a Faculdade de Tecnologia do Tatuapé - Victor Civita, no ano de 2015. Tal instituição é uma das 66 unidades de ensino superior do Centro Estadual de Educação Tecnológica Ceeteps - e oferta quatro cursos: Construção de Edifícios, Transportes Terrestres, Controle de Obras e Gestão Empresarial na modalidade EAD.

Cabe destacar que a unidade atua na área de infraestrutura e seus cursos estabelecem parâmetros e estão organizadas pelos seus devidos conselhos:

a) Atuar nas diversas áreas da construção civil aplicando os conceitos do controle aos inúmeros sistemas produtivos a fim de apontar e fiscalizar a obra visando implantar os padrões tecnológicos especificados em projetos e indicados em normas técnicas gerando, assim, a otimização de custos e recursos, com qualidade e segurança;

b) Atuar em instituições do setor público ou privado projetando, fiscalizando e acompanhando obras sobre aspectos de segurança, legislação ambiental, gestão e controle, interpretação de projeto, normas, monitoramento das etapas da obra, e conduzindo equipes, gerenciando e fiscalizando os processos construtivos.

c) Atuar em empresas de construção visando controle de qualidade, execução de ensaios laboratoriais, instalação laboratorial, calibragem de equipamentos e avaliação de resultados.

Essa atuação formaliza a inserção social, proposta inicial da instalação de Fatecs em uma área de grande concentração de construtoras, prédios comerciais e residenciais; forte explosão demográfica e alto índice de desenvolvimento urbano e local. 


\section{Procedimento de coleta de dados}

A pesquisa foi realizada com alunos que se inscreveram para o vestibular, acessaram a uma vaga e, em algum momento, tomaram a decisão de deixar de frequentar a Fatec Tatuapé, seja por motivo de trancamento, desistência formal ou informal, no ano de 2015. Os participantes estavam matriculados em um dos cursos ofertados pela instituição de ensino, totalizando 189 respondentes.

Para a coleta de dados foi enviado um questionário para cada ex-aluno, por meio eletrônico, com um total de 24 itens, sendo 22 questões fechadas e duas abertas. Para a análise dos dados foram utilizados oito itens deste questionário, que dizem respeito ao perfil do aluno que não permaneceu na unidade de ensino. A motivação deste em deixar de frequentar a faculdade será abordada em um trabalho futuro, devido à complexidade da análise de conteúdo e do tratamento discursivo das respostas abertas e também pela limitação de tempo.

O questionário permaneceu na plataforma SurveyMonkey a partir do dia 24 de novembro de 2015 e foi finalizado em 14 de dezembro de 2015, pois não era mais acessado e respondido por alguns dias seguidos, sendo suas respostas tratadas posteriormente. As questões utilizadas foram extraídas do portal de avaliação institucional Web SAI, ferramenta utilizada desde 2010 pelo Ceeteps do Estado de São Paulo para avaliar as escolas técnicas, as faculdades de tecnologia e a administração central desse órgão. Decidiu-se utilizar as questões do Web SAI, pois, os itens já haviam passado pela validação de um conselho de ética e estavam alinhadas aos objetivos desta pesquisa, além de já terem sido testadas e aperfeiçoadas em anos anteriores.

Foram consultados também os dados de matrícula da Fatec Tatuapé no ano de 2015, dados fornecidos pelo Sistema de Gerenciamento e Acompanhamento Acadêmico, acessado para comparar o perfil dos alunos ingressantes com o dos desistentes.

\section{Os resultados}

O questionário foi respondido por 78 pessoas, representando $41,3 \%$ dos desistentes da Fatec Tatuapé no ano de 2015. Cabe destacar a relativa dificuldade em entrar em contato com alunos que não mais frequentam a unidade de ensino, uma vez que estes, de certa forma, cortam o vínculo com a unidade e não se interessam mais em colaborar com as atividades da mesma. Apresentam-se a seguir, as respostas obtidas através das perguntas objetivas.

Ao analisar a tabela 1 foi possível perceber que o curso com maior evasão, dentre os alunos respondentes, foi o de Controle de Obras. O curso de Gestão Empresarial também teve uma alta taxa de desistência, mas é o curso que teve menor número de matrículas. 
Tabela 1 -

Curso em que os participantes estavam matriculados.

\begin{tabular}{|c|c|c|}
\hline Curso & Total & $\%$ \\
\hline Construção de Edifícios & 21 & $26,9 \%$ \\
\hline Transportes Terrestres & 6 & $7,7 \%$ \\
\hline Controle de Obras & 26 & $33,3 \%$ \\
\hline Gestão Empresarial & 25 & $32,1 \%$ \\
\hline
\end{tabular}

Os alunos pesquisados estavam matriculados, principalmente, no período noturno, como mostra a tabela 2. Note-se que pouco mais de $60 \%$ dos alunos da faculdade se matricularam em um curso oferecido neste período.

Tabela 2 -

Turno do curso frequentado.

\begin{tabular}{|c|c|c|}
\hline Turno & Total & $\%$ \\
\hline Matutino & 13 & $16,7 \%$ \\
\hline Vespertino & 11 & $14,1 \%$ \\
\hline Noturno & 30 & $38,5 \%$ \\
\hline EAD & 24 & $30,8 \%$ \\
\hline
\end{tabular}

Pela tabela 3 tem-se que pouco mais da metade dos alunos (52,6\%) tinha entre 20 a 35 anos de idade, sendo apenas $7,7 \%$ menores de 20 anos. Parte expressiva da amostra $(39,8 \%)$ tinha mais do que 35 anos, valor elevado comparado com a quantidade de ingressantes nesta faixa etária $(28,1 \%)$.

Tabela 3 -

Idade dos participantes.

\begin{tabular}{|c|c|c|}
\hline Idade & Total & $\%$ \\
\hline Menos de 20 anos & 6 & $7,7 \%$ \\
\hline de 20 a 25 anos & 21 & $26,9 \%$ \\
\hline De 26 a 30 anos & 12 & $15,4 \%$ \\
\hline De 30 a 35 anos & 8 & $10,3 \%$ \\
\hline De 35 a 40 anos & 10 & $12,8 \%$ \\
\hline De 40 a 45 anos & 8 & $10,3 \%$ \\
\hline Mais de 45 anos & 13 & $16,7 \%$ \\
\hline
\end{tabular}

A quantidade de alunos que se afastaram da faculdade é majoritariamente masculina $(67,9 \%)$, taxa muito próxima à de homens que se matricularam $(67,3 \%)$. 
Quando questionados a respeito de sua situação no mercado de trabalho a maioria dos respondentes encontra-se empregado (86\%), sendo $57,7 \%$ trabalhando fora da área do curso e $28,2 \%$ na área do curso que estava matriculado. Importante destacar que no momento da matrícula $66,8 \%$ estavam em exercício profissional.

Pela tabela 4 vê-se que a maior parte dos respondentes são ex-alunos do $1^{\circ}$ e $2^{\circ}$ semestres. A tendência observada é que, à medida que $o$ aluno avança no curso, menor é o índice de desistência no semestre.

Tabela 4 -

Semestre que o aluno trancou ou abandonou o curso.

\begin{tabular}{|c|c|c|}
\hline Semestre & Total & $\%$ \\
\hline $1^{\circ}$ semestre & 34 & $43,6 \%$ \\
\hline $2^{\circ}$ semestre & 23 & $29,5 \%$ \\
\hline $3^{\circ}$ semestre & 11 & $14,1 \%$ \\
\hline $4^{\circ}$ semestre & 5 & $6,4 \%$ \\
\hline $5^{\circ}$ semestre & 1 & $1,3 \%$ \\
\hline $6^{\circ}$ semestre & 4 & $5,1 \%$ \\
\hline Nunca frequentou & 0 & $0,0 \%$ \\
\hline
\end{tabular}

Um terço dos entrevistados disse já ter concluído algum curso de ensino superior. Sobre ter concluído ou não algum curso técnico $32,1 \%$ disseram ter concluído, mas fora da área do curso em que estava matriculado e $26,9 \%$ disseram que concluíram algum curso na área de curso superior.

\section{Considerações gerais}

Com base nas respostas obtidas pelo questionário pode-se estabelecer um perfil do aluno desistente na unidade de ensino superior tecnológico, bem como refletir sobre possíveis atitudes e ações para iniciar o processo de acolhimento e permanência do aluno nesta unidade.

O primeiro ponto a ser analisado é a desistência por curso. É importante recordar que 0 aluno ingressante chega ao ambiente escolar geralmente com altas expectativas em relação ao curso, infraestrutura, procedimentos didáticos, tempo necessário para estudo. Assim que as aulas começam inicia-se uma nova rotina, com tarefas que demandam conhecimento prévio em algumas disciplinas, tempo, esforço e dedicação e que muitas vezes ele não se encontra preparado e nem habituado para acompanhar as aulas do ensino superior. A ideia de frequentar o ensino superior com o mínimo de esforço pode levá-lo ao abandono, à desistência, mas deve provocá-lo a ultrapassar barreiras e avançar. No entanto, às vezes a realidade diária do estudante se revela muito mais inesperada e difícil de ser vivenciada, uma vez que este aluno vem normalmente do ensino público e traz grandes dificuldades a serem superadas, além de conciliar estas atividades com seu trabalho.

O tempo investido no trabalho pode gerar a desmotivação, com a qual as unidades de ensino superior neste momento convivem. A não correspondência entre expectativa e 
realidade em relação à vida acadêmica, dificuldade em lidar com uma rotina diferente e abdicar do tempo livre para estudar podem frustrar muitos alunos.

Observando a realidade da Fatec Tatuapé nota-se que boa parte dos desistentes estavam matriculados no curso oferecido à distância. A ideia de não precisar frequentar o ambiente escolar diariamente e estudar a hora que the for mais conveniente pode ser, muitas vezes, uma armadilha, já que esta modalidade exige sim esforço diário de algumas horas e se o aluno não se organizar acumulará conteúdos a estudar e acabará sobrecarregado de atividades e ainda com dificuldades de acompanhar as dinâmicas impostas por esta modalidade de ensino.

Outro fator importante no EAD é o ambiente virtual de aprendizagem. Além de estudar e aprender o conteúdo proposto pelo curso exige-se que o aluno saiba conceitos intermediários de informática e que tenha certa destreza ao operar o ambiente de aprendizagem. Se o aluno não receber assistência em relação a isso terá dificuldade em frequentar o curso e participar das atividades. O público mais velho sente uma maior dificuldade em relação a essa modalidade de ensino, além de sentir falta do contato pessoal oferecido por um curso presencial.

A maior parte dos alunos frequentava o período noturno, cujo público alvo costuma ter uma faixa etária maior, em função das atividades laborais e essa rotina dupla pode promover maior possibilidade de desistência e menor preocupação com a escola. Desse modo, o trabalho supera as suas expectativas com relação a sua profissionalização e sua vida acadêmica e ressalta-se sua rotina diária de trabalhador.

\section{Referências}

BRANDÃO, Carlos da Fonseca. Apontamentos sobre política educacional pública brasileira para a educação tecnológica e profissional nas últimas décadas. In: ALMEIDA, Ivanete Bellucci P; BATISTA, Sueli Soares dos Santos (orgs.). Educação tecnológica: reflexões, teorias e práticas. Jundiaí: Paco, 2012, p. 63-76.

MOTOYAMA, Shozo. Educação técnica e tecnológica em questão: 25 anos do Ceeteps uma história vivida. São Paulo: Unesp, 1995.

ROMANELLI, Otaíza de Oliveira. História da educação no Brasil. Campinas: Autores Associados, 1978.

Rodrigo Vieira Campos é estudante do curso de mestrado em gestão e desenvolvimento da educação profissional pelo Centro Estadual de Educação Tecnológica Paula Souza de São Paulo.

Endereço: Avenida Tiradentes, 615 - 01101- 010 - São Paulo - SP - Brasil.

E-mail: c.rodrigo@outlook.com.

Ivanete Belucci Pires de Almeida é doutora em educação pela UNICAMP e professora do programa de pós-graduação do Centro Estadual de Educação Tecnológica Paula Souza de São Paulo.

Endereço: Avenida Tiradentes, 615 - 01101- 010 - São Paulo - SP - Brasil.

E-mail: ivanete.bellucci@fatec.sp.gov.br.

Recebido em 29 de junho de 2016.

Aceito em 21 de novembro de 2016. 